\title{
EXPRESSÕES DE MICROAGRESSÕES DIRIGIDAS A MULHERES NO CONTEXTO DO SISTEMA DE SAÚDE: UMA ABORDAGEM BASEADA EM INCIDENTES CRÍTICOS ${ }^{1}$ \\ EXPRESSIONS OF MICROAGGRESSIONS AGAINST WOMEN IN THE HEALTHCARE CONTEXT: A CRITICAL INCIDENT APPROACH
}

\author{
Elena Piccinelli², Sara Martinho ${ }^{3}$, Christin-Melanie Vauclair ${ }^{4}$ \\ PSIQUE • E-ISSN 2183-4806 • VOLUME XVI • ISSUE FASCÍCULO 1 \\ $1^{\text {ST }}$ JANUARY JANEIRO - 30 ${ }^{\text {TH }}$ JUNE JUNHO 2020 •PP. 44-64
}

DOI: https://doi.org/10.26619/2183-4806.XVI.1.3

Submited on April, 2020

Submetido em abril, 2020

\section{Resumo}

Objetivo. Os pacientes pertencentes a minorias sociais podem ser expostos a várias formas de discriminação no contexto de cuidados de saúde. A investigação prévia nesta área não tem dado especial atenção às manifestações de microagressões dirigidas às mulheres e ao papel das identidades interseccionais. O presente estudo tem como objetivo realçar os temas subjacentes às manifestações de microagressões vividas por diversas mulheres em Portugal.

Método. Recorrendo ao modelo de entrevista baseado na Técnica de Incidentes Críticos (Flanagan, 1954), entrevistaram-se 17 mulheres a propósito das microagressões vividas no contexto de cuidados de saúde. Entre as identidades interseccionais, algumas mulheres pertenciam a grupos minoritários baseados na etnicidade, LGB e diversidade funcional.

Resultados. Foram identificados 17 temas relativos às microagressões, cinco dos quais dirigidos às mulheres no geral, e sete dirigidos às mulheres com identidades interseccionais específicas. Outros quatro temas refletiram atitudes microagressivas dos profissionais de saúde dirigidas a pacientes no geral, sem relação com o género ou à pertença a outras minorias sociais, e um tema foi criado para descrever microagressões sistémicas.

Conclusões. Alguns dos temas encontrados foram relacionados com microagressões que as mulheres vivem no dia-a-dia, sendo agravados pela disparidade de poder entre profissionais de saúde e pacientes. Outros temas pareceram ser específicos do contexto de saúde e relacionados com a falta de abordagens centradas no/a paciente.

Palavras-chave: Microagressões, Cuidados de Saúde, Mulheres, Interseccionalidade, Incidentes Críticos

\footnotetext{
${ }^{1}$ Este trabalho foi apoiado pelas subvenções atribuídas aos segundo e terceiro autores pela Fundação Portuguesa para a Ciência e Tecnologia (PD/BD/135343/2017 e IF/00346/2014)2014). This work was supported by the grants awarded to the second and third authors by the Portuguese Foundation for Science and Technology (PD/BD/135343/2017 and IF/00346/2014)

2 Instituto Universitário de Lisboa, ISCTE-IUL, Lisboa, Portugal. elena_piccinelli@iscte-iul.pt

3 Instituto Universitário de Lisboa, ISCTE-IUL, CIS-IUL, Lisboa, Portugal. soqmo@iscte-iul.pt

${ }^{4}$ Instituto Universitário de Lisboa, ISCTE-IUL, CIS-IUL, Lisboa, Portugal. Melanie.Vauclair@iscte-iul.pt
} 


\begin{abstract}
Purpose Patients belonging to social minorities can be exposed to various forms of discrimination in the healthcare context. Previous research in this domain has overlooked expressions of microaggressions against women and the role of intersectional identities. This study aims to uncover the themes that underly the experience of microaggressions by diverse women in Portugal.

Methods Using an interview model based on the Critical Incident Technique (Flanagan, 1954) 17 women were interviewed about their microaggression experiences in the healthcare setting. Among those with an intersectional identity, social minority membership was also based on ethnicity, LGB sexual orientation and functional diversity.

Results A total of 17 microaggressive themes were retrieved, five of which were found to be related to microaggressions towards women in general and a total of seven were unique for women with specific intersectional identities. Another four themes reflected providers' general attitudes towards patients without being related to gender or any intersectional minority group, and one theme described systemic microaggressions.

Conclusion Some of the retrieved themes reflect microaggressions that women seem to experience in their everyday life but that are exacerbated by the health provider-patient power disparity. Some themes appear to be specific to the healthcare context and related to providers' lack of patient-centeredness.
\end{abstract}

Keywords: Microaggressions, Healthcare, Women, Intersectionality, Critical Incidents

Discrimination in the form of racism, sexism, heterosexism or ableism have taken new forms of expressions over the past decades. While blatant manifestations seem to be almost disappearing, subtle forms of discrimination have been emerging and becoming more prominent in many Western societies (Dovidio \& Gaertner, 2000). To date, a large share of social psychological research on subtle discrimination focuses on perpetrators to better understand their biases, stimulated by the insight that anti-prejudice norms in Western societies changed the expression of prejudice from overt to covert, especially in regard to race relations in the United States. This modern form of race prejudice has been labelled in various ways such as symbolic racism (Sears, 1988), aversive racism (Dovidio \& Gaertner, 2004), racial ambivalence (Katz, Wackenhut, \& Hass, 1986), or modern racism (McConahay, 1983; Pettigrew, 1989). Similar conceptual developments occurred in the area of sexism such as ambivalent sexism (Glick $\&$ Fiske, 2001), modern sexism (Swim, Aikin, Hall, \& Hunter, 1995), and neosexism (Tougas, Brown, Beaton, \& Joly, 1995).

More recently, a new research paradigm within the area of counselling and clinical psychology has emerged, focusing on the targets and examining how they experience subtle forms of discrimination (Sue et al., 2007). Within this paradigm, subtle discrimination has been framed under the label of microaggressions, which are defined as the slights, insults, invalidations or indignities that are directed at minority, marginalized and discriminated groups and which communicate derogatory and hostile messages (Sue, 2010). They are often delivered by well-intentioned individuals who are not aware of the discriminatory implicit message they are sending. 
Within this framework, many authors (Capodilupo et al., 2010; Nadal et al., 2015; Sue, 2010) have conducted seminal qualitative research and showed that there are different microaggressive themes reflecting the experience of various social minority groups. Some of these themes tap into stereotypes and prejudices as already identified in the social psychological literature that focuses on the perpetrators' perspective (e.g., benevolent sexism, Glick \& Fiske, 2001). Yet, other microaggressive themes seem to tap into basic social categorization and identification processes (e.g., the theme 'alien in own country' referring to the ethnic majority's belief that visible racial/ ethnic minority citizens are foreigners). Hence, microaggressions are multifaceted and there are still many unknowns, such as how microaggressions are expressed in different societies. Moreover, the issue of intersectionality has recently attracted increased attention in the literature but rarely been examined in regard to microaggressions. There is an urgent need for more studies to be conducted outside the United States (US) in order to better understand what kinds of microaggressions particular social minorities experience in a specific socio-cultural context and life domain. This study aims to address these research gaps by examining the type of microaggressions that women belonging to multiple social minorities experience in the healthcare context in Portugal.

\section{Microaggressions in the Healthcare Context}

Microaggressions have been studied in various domains to date (e.g., counselling, workplace) with the healthcare context being a highly relevant one because health providers occupy a position of social power and authority and patients find themselves in a situation of heightened vulnerability (Cruz et al., 2019; Saha et al., 2008). This power disparity is exacerbated when patients belong to socially disadvantaged minority groups (Vissandjée et al., 2001) creating ideal conditions for the expression of well-intentioned but microaggressive messages. Previous research has already shown that microaggressions can have harmful consequences on targets' health and psychological wellbeing (Nadal et al., 2014; Nadal et al., 2016). Moreover, the experience of microaggressions in the healthcare context can also be regarded as lacking patient-centeredness which has shown to be harmful regarding treatment adherence, patients' trust and satisfaction and general medical outcomes (Taylor, 2009). Hence, experiencing microaggressions in the healthcare domain may also jeopardize minority members' health outcomes rendering it a topic of utmost relevance.

Previous qualitative research on microaggressions in the healthcare context mainly focused on uncovering the microaggressive themes as experienced by minorities belonging to one particular socially disadvantaged group (Almond, 2017; Cruz et al., 2019; Feagin \& Bennefield, 2014; Frankset al., 2005; Hobson, 2001). Only very few studies focused on microaggressions experienced by women in the healthcare domain. Among the most relevant studies is the one conducted by Smith-Oka (2015). She conducted ethnographic fieldwork to study interactions between health providers and obstetric patients in Mexico and found that microaggressions in clinical encounters were related to the following overarching themes: 1) perceptions of suitability for good motherhood; 2) moralized versions of modern motherhood inscribed on patient bodies; 2) a priori assumptions about the hypersexuality of low-income women; and 4) clinician frustration exacerbated by overwork resulting in corporeal violence. Even though this study provides 
insights into microaggressions experienced by women in medical encounters, it is embedded in the very specific healthcare context of obstetrics in Mexico.

There is also one recent qualitative study on microaggressions experienced by LGBTQI + minority members in the medical healthcare context which identified the following themes: Endorsement of Heteronormative or Gender Normative Culture and Behaviours, Discomfort With or Disapproval of LGB or Transgender Experience, Environmental Microaggressions and Systemic Microaggressions (Dean et al., 2016). This study focused generally on sexual orientation, without specifically considering the experiences of self-identified women. Nevertheless, it provides a first glimpse into the microaggressive themes that may underly the experiences of LGBTQI + populations in the healthcare context. Particularly interesting is the theme Systemic Microaggressions which "manifest in institutional organization and policy (both de jure and de facto), including educational programming and curricula", and are closely linked to the lack of diversity trainings for health professionals (Dean et al., 2016). These type of microaggressions go well beyond interpersonal expressions of biases and point to the larger systemic and structural problems of discrimination that are engrained in society.

Finally, Snyder et al. (2018) conducted a study in the U.S. on multiracial male and female patients. They found that microaggressions were driven by health providers making mistaken assumptions about patients' ethnic identity, family kinship and income class or degree of education based on their physical attributes. They also found that intersectionality was an important reason for attributing microaggressions or feelings of awkward encounters in health care because participants could not attribute them just to race. This is an important finding because it suggests that intersectionality may be an important issue for the experience of microaggressions. Yet, Snyder et al. (2018) did not further examine how intersectionality may play a role for the type of microaggressions that their intersectional patients experienced.

Intersectionality has recently become a buzzword in psychology and is well integrated into feminist writings in the social sciences (Else-Quest $\&$ Hyde, 2016). Intersectionality evolved from Black Feminism and Critical Race Theory and is a theoretical and analytical approach emphasizing that social experiences are shaped by multiple categories of identity, difference, and inequality (e.g., gender, race, sexual orientation, disability and others) (Cole, 2009). It can be defined as the interconnected nature of social categorizations as they apply to a given individual or group, which create overlapping and interdependent systems of discrimination or disadvantage (Oxford University Press, 2019). In other words, people with different minoritarian identities may not simply experience discrimination based on the separate social groups they belong to (e.g., racism or sexism) but they are subjected to specific forms of prejudice related to the intersection of their identities as is the case of the phenomenon of gendered racism (Lewis $\&$ Neville, 2015). This may expose individuals to microaggressions of a somewhat different nature (Nadal, et al., 2015; Sue, 2010). For example, Nadal et al. (2015) recently demonstrated that microaggressions towards people with intersectional identities contain themes that are different to those that have been established for non-intersectional minorities: women of color described experiences related to exotization, or ambiguous compliments about their appearance, while lesbian women appeared to be exposed to gender-based stereotypes related to masculinity.

In this study, we aim to examine microaggressions experienced by women in the health care context in Portugal by taking into account that intersectional identities can give rise to different experiences. We consider that social identities are multifaceted and can include different 
minoritarian and intersectional identities. Hence, our overall research question is: What type of microaggressions do women and those with intersectional identities experience in the health care domain in Portugal? To the best of our knowledge, this is the first study that aims to answer this question in the Portuguese socio-cultural context.

\section{Methods}

\section{Participants}

Female participants were recruited through personal contacts and via snowball sampling within the activist community. Participants were deemed eligible if they were activists or highly committed to social minority causes which was established as an eligibility criterium because the ability to recognize subtle discriminatory acts, such as microaggressive incidents, should be greater when women have developed an actively committed identity (Capodilupo et al., 2010; Downing \& Roush, 1985). This approach made it more likely to reach a point of saturation with a relatively small number of interviews.

The sample was composed of 17 women belonging to different social minorities with 6 self-identifying just as Portuguese women and 11 indicating intersectional identities, i.e. identifying themselves also with a LGB minority group $(n=5)$, or with a specific ethnic minority $(n=4)$, or as a functionally diverse woman ( $n=2)$. Participants' age ranged from 23 to 59 years $(M=38)$. Sixteen of them self-identified with the feminine gender, one participant self-identified with non-binary gender. All participants had Portuguese nationality, three of them also had a second nationality. All participants self-identified as activists and/or feminists. Fourteen of them defined themselves as 'formal activists' (meaning that they usually engage in activities with associations, organizations and other entities that openly work with activism), while three of them defined themselves as 'informal activists' (intending activism as an every-day contribution through interpersonal relations, work activities, research activities, etc.). As activists, participants expressed their interest in different forms of activism, such as feminism, ethnic activism, activism for LGBTQI + people's rights, activism for functionally diverse people's rights, and intersectional forms of activism.

\section{Procedure}

\section{Instruments}

The development of the semi-structured interview guide relied on previous literature about microaggressions (e.g., Capodilupo et al., 2010) and discrimination in the health care, as well as on Flanagan's Critical Incident Technique (1954). The latter aims to identify the observation of human behavior that has critical significance for the target person. Critical incidents refer to situations which are remembered because they are perceived as problematic, upsetting or confusing. This makes it a highly suitable method for the identification of microaggressions by individuals who are highly committed to social minority causes because they are more likely to appraise and remember situations as critical and as reflecting a subtle form of discrimination (Capodilupo et al., 2010; Downing \& Roush, 1985). The use of this technique can provide the 
researcher with a rich description of the microaggressive incident, according to the perspective and to the subjective reality of the interviewee. The subjectivity of the experience and appraisals of microaggressive incidents is a key element of the microaggressions framework (Sue, 2010). This technique also offers the opportunity to construct short vignettes that can be used for training purposes to sensitize enactors of microaggressions and illustrate how they are experienced by the targets. Critical incidents have been used in a wide range of disciplines, such as Nursing, Medicine, and Psychology. In particular Intercultural Psychology has made use of critical incidents for training purposes to sensitize individuals about specific issues, and to trigger empathy, raise awareness and stimulate critical thinking (Herfst et al., 2008). Yet, to the best of our knowledge this technique has not been used to extract and illustrate microaggressive themes in the healthcare context.

The interview guide started with a definition of microaggressions and some very general examples. At the end of the introduction, the interviewer used the critical incident technique (Flanagan, 1954) to elicit concrete accounts of experiences with microaggressions directed at the interviewee or other people that had occurred in the healthcare context. Open-ended questions followed in order to probe into the details of the incident and to facilitate the remembrance of the situation of microaggression (Gremler, 2004) (e.g., the actors involved, the emotions felt, the perceived cause of the incident, the psychological and practical consequences, etc.). The memory of one incident often triggers the memory of similar incidents (Edvardsson \& Roos, 2001). Hence, the same set of questions was repeated for each incident described. At the end of the interview, questions about personal details (age, gender, identification with social minorities, details about their engagement as activists) were asked.

A pilot study was conducted in order to test the interview guide. Four women participated in the pilot and were given instructions to recall microaggressive incidents either before or during the interview took place. Participants who had received the instructions before the interview remembered about twice as many incidents of microaggressions and were able to provide more details in their description than those who received the instruction during the interview. For this reason, it was decided to provide all participants of the main study with the instruction prior to the interview.

\section{Data collection}

Interviews were conducted in Portugal, between March and May 2019 and followed the ethical principles and code of conduct for psychologists as stipulated by the American Psychological Association (APA). The informed consent ensured that participation was voluntary, anonymous and confidential. The principle of saturation (Saunders et al., 2018) was reached after interviewing 17 participants. Out of 17 interviews, 12 were conducted face-to-face, three were conducted on video-call and two via telephone. The interviews' duration lasted on average 27 minutes. All interviews were conducted by the same interviewer, in Portuguese, were audio-recorded, and transcribed verbatim. Quotes reported in the results section were translated from Portuguese to English.

\section{Data Analysis}

A thematic analysis was conducted with NVivo to identify specific themes within the data to help understand the meanings of the microaggressive incidents (Braun et al., 2018). The chosen 
unit of coding consisted of segments of conversation that represented a single message or a distinguishable feature relevant for each created node. The length of these units differed and was determined by the coder, a valid approach when the analysis is conducted on semi-structure interviews containing open-ended questions with free-flowing text data (Kurasaki, 2000). For our analysis, we first inductively identified and labelled categories of microaggressive incidents based on specific underlying themes. The coded segments were first categorized deductively, i.e. based on themes that had already been established in the literature about microaggressions. When this was not possible, we created new themes considering the social psychological literature about stereotyping and discrimination. A total of 17 microaggressive themes were identified with this approach which can be seen in Table 1.

Peer debriefing was repeatedly done during the different phases of the study. Codes and coding procedures were reviewed and discussed within the research team to mitigate biases due to the researcher's subjective judgments (Coutinho, 2008). Moreover, a third researcher reviewed the coding of two interviews, which were randomly selected ( $20 \%$ of all collected data) and stated whether they agreed or disagreed with each code.

\section{TABLE 1}

Microaggressive Themes

\begin{tabular}{|c|c|c|}
\hline Microaggressive themes & Frequencies & Definition \\
\hline \multicolumn{3}{|r|}{ Women in general } \\
\hline 1. Ascription of inferiority & 8 & $\begin{array}{l}\text { Related to the belief that women are too emotional and hypochondriac, and not } \\
\text { able to decide for their health neither to understand their own health issues. }\end{array}$ \\
\hline $\begin{array}{l}\text { 2. Assumption of traditional } \\
\text { gender roles }\end{array}$ & 1 & $\begin{array}{l}\text { Related to the belief that women should follow the gender roles prescribed by } \\
\text { society, especially in the context of family care. }\end{array}$ \\
\hline 3. Moralization & 4 & $\begin{array}{l}\text { Microaggressions related to this theme were found to be triggered when } \\
\text { women were believed to be breaking moral norms related to feminine sexuality } \\
\text { and pregnancy. }\end{array}$ \\
\hline 4. Female objectification & 6 & $\begin{array}{l}\text { Includes any attitude that treats women like objects, depriving them of their } \\
\text { value as human beings. }\end{array}$ \\
\hline 5. Pain endurance & 4 & $\begin{array}{l}\text { Related to the belief that women have a lower pain endurance, are more } \\
\text { sensitive to pain and more willing to report it. }\end{array}$ \\
\hline \multicolumn{3}{|r|}{ LGB women } \\
\hline 6. Assumption of abnormality & 3 & $\begin{array}{l}\text { Related to the belief that LGB women are socially deviant or sick, and that } \\
\text { homosexuality, bisexuality, transsexuality and intersexuality are something } \\
\text { unnatural and abnormal }\end{array}$ \\
\hline $\begin{array}{l}\text { 7. Endorsement of } \\
\text { heteronormativity }\end{array}$ & 5 & Refers to providers' assumptions a priori that their patients are heterosexual. \\
\hline \multicolumn{3}{|r|}{ Ethnic minority women } \\
\hline 8. Second-class citizenship & 5 & $\begin{array}{l}\text { Refers to the treatment of women belonging to ethnic minorities as inferior or } \\
\text { as "lesser persons" }\end{array}$ \\
\hline 9. Exotization & 2 & $\begin{array}{l}\text { Related to the sexualization and objectification of black women and their } \\
\text { bodies and to assumptions on hyper-fertility, sexual promiscuity and lack of } \\
\text { family planning }\end{array}$ \\
\hline 10. Invisibility & 2 & Refers to the invisibilization of women belonging to ethnic minorities \\
\hline
\end{tabular}




\begin{tabular}{|c|c|c|}
\hline Microaggressive themes & Frequencies & Definition \\
\hline \multicolumn{3}{|r|}{ Functionally diverse women } \\
\hline 11. Desexualization & 1 & Refers to the belief that functionally diverse women are asexual beings \\
\hline 12. Insensitivity & 4 & $\begin{array}{l}\text { Includes any attitude of insensitivity and lack of empathy towards people with } \\
\text { functional diversity and their condition }\end{array}$ \\
\hline \multicolumn{3}{|c|}{ Patients as a disadvantaged group } \\
\hline 13. Attitude of superficiality & 3 & Refers to providers' attitudes of superficiality during consultations. \\
\hline 14. Lack of sensitivity-empathy & 3 & $\begin{array}{l}\text { Refers to providers' lack of sensitivity or empathy for patients' health condition, } \\
\text { illness or emotional status. }\end{array}$ \\
\hline 15. Reduction to body parts & 2 & $\begin{array}{l}\text { It refers to the treatment of patients as objects, as mere bodies with illnesses, } \\
\text { without their own feelings, willingness, personality and history. }\end{array}$ \\
\hline 16. Paternalization & 2 & $\begin{array}{l}\text { Health providers often assume a position of authority towards their patients, } \\
\text { lacking in effective communication and invalidating their experiences. }\end{array}$ \\
\hline \multicolumn{3}{|l|}{ 17. Systemic Microaggressions } \\
\hline- & 16 & $\begin{array}{l}\text { Occurs at the systemic level, being embedded both in formal and informal } \\
\text { practices, explicit or subtle norms of organizational structures. }\end{array}$ \\
\hline
\end{tabular}

\section{Results}

\section{Microaggressions against Women in General Ascription of Inferiority}

Many women mentioned situations in which health providers treated them as unable to understand their clinical conditions and that health providers claimed them to be highly anxious or hypochondriac underscoring their perceived weakness and inferiority.

"And he always has those phrases that cost me a little to listen to because he says, 'Marta* is very anxious, Marta is always very anxious "” [IP 2, 34 years; *Name was changed]

\section{Prescription of Traditional Gender Roles}

Interviewees recalled situations of interaction with health providers in which their social roles as women, mothers and caregivers were taken for granted.

"During the period of hospitalization [of my recent-born daughter] I rarely received information about my baby. Information was always given to the father, [...] And there was this issue, that the mother, clearly, the mother is a caregiver and the father is the decider. [...]." [IP 11, 33 years]

\section{Moralization}

Participants reported that health providers assumed microaggressive attitudes in situations in which patients were perceived to break moral norms related to feminine sexuality and pregnancy. 
"Once, when I was a kid; I was 12 years old, [...], and I suddenly started having a hip pain, and at the time I didn't know what it was. [...]. So, I was in a lot of pain [...] and had to go to the doctor and the nurse... [...] The nurse was so, she was mean to me. I didn't know what it was, I was still a virgin at the time, and she said to me: 'Ah, this is what you get from the men you sleep with." [IP 10, 49 years]

\section{Female Objectification}

Participants expressed feeling treated like objects, being deprived of their value as human beings. For example, many women described the feeling of being treated as reproduction machines during maternity and childbirth, particularly in medical specialties as gynecology and obstetrics.

"I think I was under 13, like 12 and 13 years old, and whenever I was wearing a bra, I had a lot of pain. [...] And I remember asking that question [to the gynecologist]. [...] And the answer I got was... [...] 'wear a sports bra on ordinary days and wear a prettier bra when you go out for parties which can be seen" [IP 6, 23 years]

\section{Pain endurance}

Many women described situations in which health providers treated them as if they were destined to suffer and endure pain, physically and psychologically, during their whole life.

"And when you say you're in pain [during childbirth], all they do is to say, and repeat it over and over again: 'Hang in there. Being a mother is like this. That's our cross. What did you think it would be like?" [IP 9, 45 years]

\section{Microaggressions against Women with Intersectional Identities}

\section{Ethnic Minority Women}

Second-Class Citizenship. Ethnic minority women reported situations in which they were treated as less worthy and less deserving which made them feel inferior and discriminated against.

"I'm Indian, and I have a complicated name. The first name, Lisa*, is simple, but the others are quite complicated. [...] when I arrived in the office of the doctor or the provider, there would always be a... how to say... condescending comment in relation to my name." [IP 8,35 years; *Name was changed]

Exotization. Women of color recalled incidents in which health providers made assumptions about their style, attractiveness and standards of beauty. Other participants described situations 
which expressed the belief that women coming from developing countries are hyper-fertile, sexually unbridled and suffer from lack of family planning.

"[...] He made a comment that... [...] It must have been about my eyes, the color of my eyes... Something like that. As if it was surprising because Cape Verdeans aren't usually so beautiful. 'The eyes are so beautiful; the skin color is so beautiful'." [IP 2, 34 years]

"Being pregnant, she experienced many situations, and being Brazilian... many situations related to be judgment of the reproductive capacity of Brazilian women. There was a doctor who told her "You Brazilians can't stay still; you're always having kids. "” [IP 10, 49 years]

Invisibility. Ethnic minority women described the feeling of being invisible, unworthy of recognition powerless and overlooked.

"First, we spent hours in the hallway of the emergency, she [the grandmother] was completely delirious from fever... And in this situation, yes, I felt invisible [...]. I believe that if I was a man [...] I would have had another type of attention. And, also, because we're Indian." [IP 8, 35 years]

"This happens many times, regardless of being or not in health situations. [...] But I remember being at the emergency department, at the hospital, and I remember being a at the entrance, to check in, (maybe it was the day of childbirth, I don't remember), there was a couple and they were being attended, and there was no one else to be attended, only me. [...] And they were attended, and when I advanced, the nurse decided at that time to staple all the papers she had and go to the doctor or whoever was in the other room. I think it was on the day of childbirth... I was feeling some pain and it was exacerbating the situation even more... [...] And I actually felt invisible and I had to do something, I had to be angry at her and to say that not even in situations of emergency people are careful enough to understand and to be, once more, sensitive. " [IP 2, 34 years]

\section{LGB Minority Women}

Assumptions of Abnormality. LGB women reported being treated as socially deviant, as if homo-, bi-, trans-, and intersexuality were something unnatural and abnormal.

"I know this lesbian girl that went to a gynecological consultation. And the doctor, it was a woman, suggested her to use some contraceptives, and she [the girl] said she didn't need to. The doctor was shocked. And the girl said 'No, it is because I like women, I am lesbian, I don't need contraceptives'. The doctor advised her to go see a psychologist [...]." [IP 6, 23 years]

Endorsement of Heteronormativity. Many LGB women recalled incidents in which health providers assumed $a$ priori that their patients were heteronormative. 
"The doctor's great concern was - it was a female doctor - [...] which contraceptive methods I used. When I said I didn't use any, [...] she gave me almost a sermon saying: 'you will get pregnant...." [IP 3, 59 years]

\section{Functionally Diverse Women}

Desexualization. Women with functional diversity reported situations in which their sexuality and sexual identity were ignored, and they were treated as asexual beings, devoid of sexual needs and desires.

"[...] it happened to me in a gynecology consultation, when I had a complicated problem... the problem had a simple solution, but their assumption was like 'Ah, it doesn't matter, as you don't need to have it [internal reproductive organs], we take everything out. Since you won't have to [...] reproduce...' [...]. They wanted to take it all out, do a general hysterectomy and remove all the organs to solve the problem." [IP 12, 52 years]

Insensitivity Towards Functionally Diverse People. Interviewees described health providers' attitudes of insensitivity towards people with functional diversity and their condition.

[Microaggression experienced by a woman on a wheelchair] "The other day I went to do an echocardiogram. And there was a big stretcher, something that you can't just put the chair underneath it to let me get on it, and I asked the lady how I was going to get on the stretcher. And she put a footstool next to me, for me to get on the stretcher." [IP 12, 52 years,]

\section{Microaggressions against Patients as a Disadvantaged Group}

Unexpectedly, participants reported some microaggressive incidents as not being related to their gender or to their intersectional identities, but to providers' attitudes of superficiality, insensitivity, objectification, and paternalization towards patients in general. These microaggressions are described below.

\section{Attitude of Superficiality}

Participants referred to attitudes of superficiality during the consultations.

“[...] A few years ago, I went to a dermatologist [...]; we had a scheduled appointment and she arrived half an hour late, the consultation lasted ten minutes and I paid - at the moment $-€ 80$. And she wasn't looking at the problem I had on my skin, she just passed the prescription." [IP 2, 34 years] 


\section{Lack of Sensitivity/Empathy}

Participants reported incidents in which they, or the patient in the situation, did not feel understood, or being treated without any sensitivity or empathy for their health condition, illness or emotional status.

"I also have a family member who had an ectopic pregnancy, so the baby got stuck in the fallopian tube and did not grow up. And it was a baby she wanted very much, it was the second child, but she really wanted to have a second child. And the doctor just said to her: 'now you probably won't have children anymore'." [IP 1, 27 years]

\section{Reduction to Body Parts}

Participants described the feeling of being reduced to the body parts to be treated, without consideration of their own feelings, willingness, personality and history (Bernard et al., 2015).

"[...] she [the doctor] started to do a pap-test, but in a way... I felt very mistreated and did not show any reaction [...] She talked a lot with the intern and little with me, so even when the intern wasn't there, she spoke less to me and looked more at the computer. [...] And then, when she was doing the pap-test, she told me to undress from the waist down and she didn't put a towel on top of me, or anything else. [..]. And I had no ability to react, I felt very exposed, because I was there, naked, the intern was a man, and she had no consideration at all." [IP 10, 49 years]

\section{Paternalization of Patients}

Many participants described situations in which health providers assumed an authoritarian position failing in facilitating a shared decision-making process and invalidating their experiences.

"I felt I had an infection of the urinary tract. It was not the first time, and, as women, I think we know when we have a urinary infection, we recognize the symptoms, etc. And I got there and said I have a urinary infection, and the doctor had that reaction that was like 'I'm going to tell you whether you have one, let's see'”. [IP 15, 31 years]

\section{Systemic Microaggressions}

During the data analysis, we also retrieved microaggressions that reflect discriminatory processes systematically built into organizational structures. Systemic discrimination is perpetrated through established practices and procedures, including both specific formal rules and informal practices embedded in organizational norms, which have become "part of the system" (Beck et al., 2002).

"I had a postpartum complication and had to be hospitalized in the intensive care. And meanwhile the two babies - they were twins - had to go to neonatology because it was 
the only place where they could stay. [...] In this context, Sofia* [the partner] experienced some unpleasant situations, for example they referred to her as 'father' [...] The mother was me who had the babies, and there can only be one mother and one father, so she was the father. Or in the sense that initially only the parents can enter... mother and father, into the neonatology ward, so they tried to ban her access because she was neither mother nor father." [IP 7, 38 years; *Name was changed]

A specific example is represented by physical barriers that impede people with functional diversity (e.g., in a wheelchair) to access specific areas.

"The medical offices, in this case within the gynecology services, are all structured for women who have a normal mobility. I can't get on a stretcher in a gynecological consultation in a public hospital or any hospital." [IP 12, 52 years]

\section{Discussion}

Microaggressions in the healthcare context are a subtle, but potentially harmful phenomenon by being unconsciously perpetrated by health providers towards patients. The main purpose of this study was to conduct a qualitative analysis in order to identify, analyze and understand microaggressive incidents towards women in the healthcare context by taking into account that women may belong to various minority groups and experience specific microaggression related to their intersectional identities. This study identified five themes based on microaggressive attitudes towards women in general and seven themes reflecting intersectional microaggressive incidents (for ethnic minority women, LGB women or functionally diverse women). Unexpectedly, we also found four microaggressive themes specifically related to providers' attitudes towards patients without being related to other forms of discrimination. Moreover, there was one theme that reflected the disadvantages and inequalities expressed in microaggressions of systemic nature. In the light of these results, there are four key contributions of our study to the literature.

First, most of the themes presented in this study match the already existing literature about sexist, racist, heterosexist, ableist and intersectional microaggressions, which validates the themes identified here, but also shows that the social relations in the healthcare context are subjected to the same discriminatory mechanisms as in other contexts. This is of great relevance because the experience of microaggressions has been linked to impaired mental health and psychological wellbeing (Nadal et al., 2014; Nadal, et al., 2016), and health care professionals may unconsciously add to the targets' cumulative experience of subtle discrimination which is particularly damaging for patients because they find themselves in a context of heightened vulnerability. In this context, the themes assumption of inferiority and traditional gender roles which can be found in the literature about gender microaggressions, are also conceptually similar to the concept of benevolent sexism proposed by Glick and Fiske. Their conceptualization of hostile sexism fits well with our microaggressive theme moralization which refers to the belief that women's sexuality is dangerous to men and to the current social hierarchy (Glick \& Fiske, 2001). The theme 
moralization, as well as female objectification, reflect the themes uncovered in Smith-Oka's (2015) study, yet are somewhat different to what she has found (Smith-Oka, 2015). This may be because the focus on obstetrics in her study narrows the perspective only to the experiences of pregnant women, which can be considered an especially vulnerable group. Interestingly, we found that these same contents were present in microaggressions experienced by non-pregnant women, being still particularly related to sexual and reproductive health. In particular, Smith-Oka (2015) found that providers' attitudes of moralization were mainly related to providers' perception of their patients capacity of being good mothers; we found these same attitudes to be related to the breaking of moral norms about female sexuality. She also found the theme of female objectification to manifest in the form of corporal microaggressions, which translate in physical forms of obstetric violence; in our study, we included in this theme those incidents, non-physically violent, in which women reported to be treated like reproductive machines. Finally, Smith-Oka (2015) found some microaggressions to be related to providers' assumptions regarding patients' unbridled sexuality: we found this theme to be recurrent in ethnic minority women as a form of exotization.

Second, this study suggests that there are some microaggressive themes that are characterized by stereotypes specific to the healthcare context, and that are not present in other contexts. The theme pain endurance, which has already been identified in studies about Gender Role Expectations of Pain (GREP) according to which women are commonly considered less able to endure pain and more willing to report it (Robinson et al., 2001; Wandner et al., 2012), was never considered in the literature about microaggressions in healthcare before. Similarly, issues of desexualization and insensitivity towards functionally diverse women have already been flagged before, but never in the framework of microaggressions (Keller \& Galgay, 2010; Scullion, 1999).

Third, the focus of this study on intersectionality has allowed us to analyze the experience of women belonging to multiple minoritarian groups. On the one side, participants with intersectional identities were able to identify microaggressions directed to the specific intersections of their identities. In other words, women belonging to an ethnic minority were found to experience certain forms of microaggressions, different from those experienced by LGB women and functionally diverse women, which in turn described microaggressive experiences unique to their groups. Previous research has already pointed to the issue of "gendered racism" (Lewis \& Neville, 2015) and ethnic minority women experiences of invisibilization, exclusion and isolation, biased compliments on appearance, and assumption of inferior status (Nadal et al., 2015; Sue, 2010). This has also emerged in the themes of this study (see second-class citizenship, invisibility and exotization). Furthermore, past studies found that LGBTQI + women experience microaggressions in the healthcare setting in the form of health providers' heteronormative assumptions (Dean et al., 2016). Previous research focusing on patient-centeredness have also emphasized that among clinicians, there is lack of knowledge of LGBTQI + health needs (Lee \& Kanji, 2017; Smith \& Turell, 2017). Lesbian mothers can be considered a particularly vulnerable category, being likely to experience forms of heterosexist invalidation and exclusion (Dahl et al., 2013; Gregg, 2018). All of these issues have also been identified in the themes of this study (see assumptions of abnormality, endorsement of heteronormativity). On the other hand, participants with intersectional identities were also found to experience microaggressions uniquely related to their gender identity as women (themes described under microaggressions towards women in general in the results). 
These results are relevant because they highlight that some themes transversally characterize the experience of all women, while others are specific to the intersection of particular identities.

Fourth, we found that some of the microaggressions did not rely on sexist, heterosexist, racist or ableist beliefs, but on patients as a disadvantaged group. Power disparities between patients and providers allow us to define patients as a social minority due to differences in status, power, rank and privileges (Tajfel, 1982). By considering microaggressions towards patients in general, we propose that microaggressions may be related not only to social stereotypes, but also to other types of mistreatment related to power disparities. The themes of attitudes of superficiality and lack of sensitivity/empathy can also be regarded as lacking patient-centeredness (Taylor, 2009) which may jeopardize treatment adherence and trust in the health care provider, and, therefore, ultimately patients' health outcomes. On the other hand, the issue of reducing to body parts and patronizing patients may be exacerbated by sexist beliefs that objectify and patronize females in particular. Hence, while some themes might also occur with male patients, others imply an exacerbation of subtle discrimination for female patients due to their overlap with sexist themes while yet other themes reflect uniquely female issues (e.g., moralization) or issues related to women with intersectional identities (e.g., exotization).

A last group of microaggressive themes was related to systemic microaggressions. In this context, an approach focused on the macro level may allow to identify and understand the systems of privilege and power, social hierarchies, symbolic systems and cultural imageries on which microaggressive incidents rely (Embrick et al., 2017). Systemic microaggressions have already been identified in previous studies and linked to deficits in institutional policies as well as in providers' education (Dean et al., 2016). In addition, we regarded systemic microaggressions as those incidents related to organizational norms and practices, formally or informally defined, which systemically discriminate a certain minority group (e.g., the non-recognition of lesbian co-mothers' role, the presence of architectural barriers impeding the acess of functionally diverse people, etc.).

The microaggressive themes presented in this study are the result of social stereotypes, discriminatory mechanisms, power disparities and lack of patient-centeredness. This could be tackled by training health care professionals with the use of short vignettes that illustrate the targets' experience. Appendix A shows a selection of critical incident vignettes based on the microaggressive themes retrieved in this research through the Critical Incident Technique. They would make an insightful training tool to render the subtleties of discrimination more visible showing how scientific results can be used for multiple practical purposes, such as in the sensitization of health providers.

\section{Limitations and future research}

The present study focused on the experience of women who self-identified as feminists and/ or activists. The choice to focus on this population was based on studies showing that individuals actively committed to social causes are usually more sensitive about discrimination, and thus may be more able to identify microaggressions which are defined as subtle forms of discrimination (Capodilupo et al., 2010; Downing \& Roush, 1985). However, the focus on this specific population and the use of snowball sampling may have restricted our perspective, overlooking the perception of those who have different backgrounds and levels of sensitivity. Future research 
should take into consideration a more diverse sample, including participants that are not activists and possibly using random sampling.

The use of semi-structured interviews is highly useful, but also bears limitations. This type of interviews creates some difficulties in terms of coding and coding comparisons, because it does not allow to select a standard unit of coding. Furthermore, as critical incidents take the shape of remembrances, scholars should pay a special attention to the relationship between human memory and time: many factors may influence the way interviewees will remember the incident, such as its valence (positive and negative incidents require different types of cognitive appraisals, and therefore are diversely stored in memory) and easiness of retrieval since the incident occurred (Edvardsson \& Roos, 2001). We suggest further research using the Critical Incident Technique to carefully consider these issues.

The present study confirms the existence of microaggressions towards women in the healthcare context but leaves some questions open. Future research should understand the degree to which men with different intersectional identities are exposed to microaggressions in the healthcare context. This would primarily allow to understand the role of gender identities in the subjective experience of different microaggressions. For example, Dean and colleagues (2016) report that HIV/AIDS prevention campaigns are often exclusively directed at gay men and almost never involve lesbian women, representing an environmental microaggression for both homosexual men and women. Studies aimed at comparing the different experiences of men and women with intersectional identities should be also conducted in the Portuguese healthcare context. Furthermore, it would be important to identify possible gender differences on the side of the enactors: do male and female health providers enact microaggressions in the same way? Do they have the same training needs? Does the gender matching of health providers and patients mitigate the phenomenon of microaggressions?

Future research should develop a scale to assess the experience of microaggressions in the healthcare context by individuals with intersectional identities. This would provide a more quantifiable insight into social minority's experience and how it relates to other outcome variables, such as treatment adherence and outcomes. In this context, other minoritarian identities (e.g., age, weight, social class, educational level) could also be taken in consideration and potentially confounding variable, such as mental health status, could also be controlled for. Even though it is unlikely that all our participants suffered from mental health issues, other researchers have already pointed out the possibility that those who perceive microaggressions might be suffering from negative affect which makes them more susceptible to perceive ambiguous messages as microaggressive (e.g., Lilienfeld, 2017). More quantitative research is needed to establish cause and effect relations and to control for such confounding variables. 


\section{References}

Almond, A. (2017). Measuring racial microaggression in medical practice. Ethnicity and Health, 1-18. https://doi.org/10.1080/13557858.2017.1359497

Beck, J. H., Reitz, J. G., \& Weiner, N. (2002). Addressing systemic racial discrimination in employment: The Health Canada case and implications of legislative change. Canadian Public Policy/Analyse de politiques, 28(3), 373-394. https://doi.org/10.2307/3552228

Bernard, P., Gervais, S. J., Allen, J., Delmée, A., \& Klein, O. (2015). From sex objects to human beings: Masking sexual body parts and humanization as moderators to women's objectification. Psychology of women quarterly, 39(4), 432-446. https://doi.org/10.1177/0361684315580125

Braun, V., Clarke, V., Hayfield, N., \& Terry, G. (2018). Thematic analysis. In P. Liamputtong, Handbook of research methods in health social sciences (p. 1-18). Springer.

Capodilupo, C., Nadal, K. L., Corman, L., Hamit, S., Lyons, O. B., \& Weinberg, A. (2010). The manifestation of gender microaggressions. In D. Sue, Microaggressions and marginality: Manifestation, dynamics, and impact (p. 193-216). John Wiley and Sons.

Cole, E. R. (2009). Intersectionality and research in psychology. American psychologist, 64(3), 170-180. https://doi.org/10.1037/a0014564

Coutinho, C. (2008). A qualidade da investigação educativa de natureza qualitativa: Questões relativas à fidelidade e validade. Educação Unisinos, 12(1), 5-15.

Cruz, D., Rodriguez, Y., \& Mastropaolo, C. (2019). Perceived microaggressions in health care: A measurement study. PLoS ONE, 14(2). https://doi.org/10.1371/journal.pone.0211620

Dahl, B., Fylkesnes, A. M., Sørlie, V., \& Malterud, K. (2013). Lesbian women’s experiences with healthcare providers in the birthing context: A meta-ethnography. Midwifery, 29(6), 674-681. https://doi. org/10.1016/j.midw.2012.06.008

Dean, M. A., Victor, E., \& Guidry-Grimes, L. (2016). Inhospitable healthcare spaces: Why diversity training on LGBTQIA issues is not enough. Journal of bioethical inquiry, 13(4), 557-570. https://doi.org/10.1007/ s11673-016-9738-9

Dovidio, J. F., \& Gaertner, S. L. (2000). Aversive racism and selection decisions: 1989 and 1999. Psychological Science, 11, 315-319. https://doi.org/10.1111/1467-9280.00262

Dovidio, J. F., \& Gaertner, S. L. (2004). Aversive racism. In M. P. Zanna (Ed.), Advances in experimental social psychology, Vol. 36 (p. 1-52). Elsevier Academic Press. https://doi.org/10.1016/S0065-2601(04)36001-6

Downing, N., \& Roush, K. (1985). From passive acceptance to active commitment: A model of feminist identity development for women. The Counseling Psychologist, 13(4), 695-709. https://doi. org $/ 10.1177 / 0011000085134013$

Edvardsson, B., \& Roos, I. (2001). Critical incident techniques: Towards a framework for analyzing the criticality of critical incidents. International Journal of Service Industry Management, 12(3), 251268. https://doi.org/10.1108/EUM0000000005520

Else-Quest, N. M., \& Hyde, J. S. (2016). Intersectionality in Quantitative Psychological Research: I. Theoretical and Epistemological Issues. Psychology of Women Quarterly, 40(2), 155-170. https://doi. org/10.1177/0361684316629797

Embrick, D. G., Domínguez, S., \& Karsak, B. (2017). More than just insults: Rethinking sociology's contribution to scholarship on racial microaggressions. Sociological Inquiry, 87(2), 193-206. https://doi. org/10.1111/soin.12184 
Feagin, J., \& Bennefield, Z. (2014). Systemic racism and US health care. Social science \& medicine, 103, 7-14. https://doi.org/10.1016/j.socscimed.2013.09.006

Flanagan, J. C. (1954). The critical incident technique. Psychological bulletin, 51(4), 327-358. https://doi. org $/ 10.1037 / \mathrm{h} 0061470$

Franks, P., Fiscella, K., \& Meldrum, S. (2005). Racial disparities in the content of primary care office visits. Journal of General Internal Medicine, 20(7), 599-603. https://doi.org/10.1007/s11606-005-0106-4

Glick, P., \& Fiske, S. T. (2001). Ambivalent sexism. In (Vol. 33, pp. 115-188). Academic Press. In M. Zanna, Advances in experimental social psychology (Vol. 33, p. 155-188). Academic Press. https://doi. org/10.1016/S0065-2601(01)80005-8

Gregg, I. (2018). The health care experiences of lesbian women becoming mothers. Nursing for women's health, 22(1), 40-50. https://doi.org/10.1016/j.nwh.2017.12.003

Gremler, D. D. (2004). The critical Incident technique in service research. Journal of Service Research, 7(1), 65-89. https://doi.org/10.1177/1094670504266138

Herfst, S. L., Van Oudenhoven, J. P., \& Timmerman, M. E. (2008). Intercultural effectiveness training in three Western immigrant countries: A cross-cultural evaluation of critical incidents. International Journal of Intercultural Relations, 32(1), 67-80. https://doi.org/10.1016/j.ijintrel.2007.10.001

Hobson, W. (2001). Racial discrimination in health care: Interview project. Public Health Seattle \& King Country.

Katz, I., Wackenhut, J., \& Hass, R. G. (1986). Racial ambivalence, value duality, and behavior. In J. F. Dovidio \& S. L. Gaertner (Eds.), Prejudice, discrimination, and racism (p. 35-59). Academic Press.

Keller, R. M., \& Galgay, C. E. (2010). Microaggressive experiences of people with disabilities. In D. W. Sue, Microaggressions and marginality: Manifestation, dynamics, and impact, (pp. 241-268).

Kurasaki, K. S. (2000). Intercoder reliability for validating conclusions drawn from open-ended interview data. Field Methods, 12(3), 179-194. https://doi.org/10.1177/1525822X0001200301

Lee, A., \& Kanji, Z. (2017). Queering the health care system: Experiences of the lesbian, gay, bisexual, transgender community. Canadian Journal of Dental Hygiene, 51(2), 80-89.

Lewis, J. A., \& Neville, H. A. (2015). Construction and initial validation of the Gendered Racial Microaggressions Scale for Black women. Journal of counseling psychology, 62(2), 289-302. https://doi. org/10.1037/cou0000062

Lilienfeld, S. O. (2017). Microaggressions: Strong claims, inadequate evidence. Perspectives on psychological science, 12(1), 138-169. https://doi.org/10.1177/1745691616659391

McConahay, J. B. (1983). Modern racism and modern discrimination: The effects of race, racial attitudes, and context on simulated hiring decisions. Personality and Social Psychology Bulletin, 9(4), 551-558. https://doi.org/10.1177/0146167283094004

Nadal, K., Davidoff, K., Davis, L., Wong, Y., Marshall, D., \& McKenzie, V. (2015). A qualitative approach to intersectional microaggressions: Understanding influences of race, ethnicity, gender, sexuality, and religion. Qualitative Psychology, 2(2), 147-163. https://doi.org/10.1037/qup0000026

Nadal, K., Griffin, K., Wong, Y., Hamit, S., \& Rasmus, M. (2014). The impact of racial microaggressions on mental health: Counseling implications for clients of color. Journal of counseling and development, 92(1), 57-66. https://doi.org/10.1002/j.1556-6676.2014.00130.x

Nadal, K., Whitman, C., Davis, L., Erazo, T., \& Davidoff, K. (2016). Microaggressions toward lesbian, gay, bisexual, transgender, queer, and genderqueer people: A review of the literature. The journal of sex research, 53(4-5), 488-508. https://doi.org/10.1080/00224499.2016.1142495 
Oxford University Press. (2019). Intersectionality. Retrieved February 12th, 2019, from English Oxford Living Dictionaries: https://en.oxforddictionaries.com/definition/intersectionality

Pettigrew, T. F. (1989). The nature of modern racism in the United States. Revue Internationale de Psychologie Sociale, 2(3), 291-303.

Robinson, M. E., Riley, J. L., Myers, C. D., Papas, R. K., Wise, E. A., Waxenberg, L. B., \& Fillingim, R. B. (2001). Gender role expectations of pain: Relationship to sex differences in pain. The journal of pain, 2(5), 251257. https://doi.org/10.1054/jpai.2001.24551

Saha, S., Beach, M., \& Cooper, L. (2008). Patient centeredness, cultural competence and healthcare quality. Journal of the National Medical Association, 100(11), 1275. https://doi.org/10.1016/S00279684(15)31505-4

Saunders, B., Sim, J., Kingstone, T., Baker, S., Waterfield, J., Bartlam, B., Burroughs, H., Jinks, C. (2018). Saturation in qualitative research: Exploring its conceptualization and operationalization. Quality $\&$ quantity, 52(4), 1893-1907. https://doi.org/10.1007/s11135-017-0574-8

Scullion, P. (1999). Challenging discrimination against disabled patients. Nursing Standard (through 2013), 13(18), 37-40.

Sears, D. O. (1988). Symbolic racism. In Eliminating racism (pp. 53-84). Springer, Boston, MA. https://doi. org/10.1007/978-1-4899-0818-6_4

Smith, S. K., \& Turell, S. C. (2017). Perceptions of healthcare experiences: Relational and communicative competencies to improve care for LGBT people. Journal of Social Issues, 73(3), 637-657. https://doi. org/10.1111/josi.12235

Smith-Oka, V. (2015). Microaggressions and the reproduction of social inequalities in medical encounters in Mexico. Social Science \& Medicine, 143, 9-16. https://doi.org/10.1016/j.socscimed.2015.08.039

Snyder, C. R., Wang, P. Z., \& Truitt, A. R. (2018). Multiracial patient experiences with racial microaggressions in health care settings. Journal of Patient-Centered Research and Reviews, 5(3), 229-238. http:// dx.doi.org/10.17294/2330-0698.1626

Sue, D. W. (2010). Microaggressions in everyday life. Race, gender, and sexual orientation. Hoboken, New Jersey: John Wiley \& Sons.

Swim, J. K., Aikin, K. J., Hall, W. S., \& Hunter, B. A. (1995). Sexism and racism: Old-fashioned and modern prejudices. Journal of Personality and Social Psychology, 68(2), 199-214. https://doi.org/10.1037/00223514.68.2.199

Tajfel, H. (1982). Social psychology of intergroup relations. Annual review of psychology, 33(1), 1-39. https:// doi.org/10.1146/annurev.ps.33.020182.000245

Taylor, K. (2009). Paternalism, participation and partnership-the evolution of patient centeredness in the consultation. Patient education and counseling, 74(2), 150-155. https://doi.org/10.1016/j.pec.2008.08.017

Tougas, F., Brown, R., Beaton, A. M., \& Joly, S. (1995). Neosexism: Plus ça change, plus c'est pareil. Personality and social psychology bulletin, 21(8), 842-849. https://doi.org/10.1177/0146167295218007

Vissandjée, B., Weinfeld, M., Dupéré, S., \& Abdool, S. (2001). Sex, gender, ethnicity, and access to health care services: Research and policy challenges for immigrant women in Canada. Journal of International Migration and Integration/Revue de l'integration et de la migration internationale, 2(1), 55-75. https:// doi.org/10.1007/s12134-001-1019-7

Wandner, L. D., Scipio, C. D., Hirsh, A. T., Torres, C. A., \& Robinson, M. E. (2012). The perception of pain in others: How gender, race, and age influence pain expectations. The Journal of Pain, 13(3), 220-227. https://doi.org/10.1016/j.jpain.2011.10.014 


\section{Annex A}

\section{Critical Incidents}

\section{Exemplary microaggressive incident towards women in general: Pain Endurance}

Maria is a 32-years-old Portuguese woman. She lives in a medium-sized Portuguese town with her husband, Luís. She is at the beginning of the last week of her pregnancy, expecting her first child.

After two hours the contractions become more regular and intense and Maria starts to be in great pain. She and Luis call a doctor who tells them to enter a room and starts examining Maria. At the end of the examination, the doctor tells Maria that everything is fine with the baby but that she is not enough dilated yet. She needs to wait more. Noticing the expression of tiredness and discomfort on Maria's face, he continues: "I know it hurts, but you are a mother now. What did you expect? This is only the beginning. This is a mother's life. You will have to endure a lot of pain from now on." Maria feels scared and confused, but she does not know what to answer. She goes back to the corridor and continues to walk. Once in a while, a health provider checks the baby heartbeats. Six hours later, she is finally ready to give birth.

\section{Exemplary microaggressive incident towards LGB women: Endorsement of heter- onormativity}

Diana is a Portuguese 25-years-old woman who is living and studying in a big Portuguese city. She moved there recently from a small Portuguese village with her partner Júlia.

One day, Diana decides to go to a gynecologist for a routine check. On the day of the appointment, Julia accompanies Diana to the clinic. Once arrived, they head to the check-in desk. The attendant nicely asks for Diana's documents and types something on a computer. Then she looks at Julia and asks her if she has an appointment, too. Julia answers that she is only accompanying Diana. When the attendant asks what their parental degree is, Julia replies that she is Diana's girlfriend. The attendant rises an eyebrow, stares at them for some seconds and then coldly answers: "Well, I am sorry, but you will have to stay in the waiting room. We only allow family members to enter." Perplexed, Julia and Diana look at each other, then they silently nod and go to the waiting room.

\section{Exemplary microaggressive incident towards ethnic minority women: Exotization}

Carol is a 30-years old woman, who immigrated together with her husband from Brazil to Portugal 10 years ago and now lives in a big Portuguese city. When Carol discovers to be pregnant of her first child, she searches for a doctor to do a first examination.

The doctor kindly welcomes her, and after a few general questions about her medical history, invites her to lie down on the stretcher for the echography. Before he starts, he looks at her and says: "You Brazilian people! You are always having kids, aren't you? You are tireless". Carol feels very uncomfortable: this is her first pregnancy and she and her husband waited to have a stable life before deciding to have a child. Lying on the stretcher while the doctor visits her, she feels vulnerable and powerless. She decides to ignore the doctors' comment and to focus on the image on the display of the ultrasound machine. 


\section{Exemplary microaggressive incident towards functionally diverse women: Insensitivity} Irene is a 45-years-old Portuguese woman living in a medium-sized town with her family. She has been on a wheelchair for five years, because of a car accident that left her paraplegic. Despite the difficulties to adapt to her condition, Irene has been able to attain a regular and happy life. Yet, she has experienced some breathing complications recently and her treating physician refers her to a specialist.

When she enters the doctors' office, a young doctor welcomes her. He seems surprised about her condition. He asks her to describe her symptoms and then to lay down on an examination table. Irene looks at the table and feels confused. It is too high, and it is impossible for her to get on it on her own. She asks the doctor how she is supposed to get on it. For some seconds, the doctor seems confused too, then he takes a footstool and places it next to the examination table. Irene feels angry. She replies: "As I already told you, I am paraplegic. I cannot move my legs. I need help." The doctor seems to understand. He apologizes and calls a technician to lift her. She knows that there is no other way, but she hates to feel moved like an object.

\section{Exemplary microaggressive incident towards patients: Paternalization and lack of sen- sitivity/ empathy}

Joana is a 38-years-old Portuguese woman. For a few weeks now, she is having a rash on both her arms and legs. She decides to schedule an appointment with a dermatologist to check the issue.

When Joana enters the dermatologists' office, he invites her to sit and asks what her problem is. While Joana answers the question, he keeps typing on his computer. He seems to be more focused on what he is writing than on what she is saying. Joana lifts a sleeve of her shirt to show him the rash. Without going any closer to her, he looks at her harm and quickly says: "Yes, I see". Joana is feeling confused now. Is he paying attention to her? Did he really understand from a simple, distanced look, what she has? She explains that she has had it for a few weeks now. She tried to use some moisturizing creams, also went to the pharmacy and asked for a pomade, but it did not work. The doctor nods while he is typing on his computer. After some minutes, he prints a prescription and hands it to her. "This is nothing serious. You should pass this pomade twice a day on the rash and take these pills once a day for two weeks. Do you understand?" Joana feels that she wants to ask more details about the instructions he gave her, but she feels very uncomfortable. "Yes, I think I understood. Can you tell me what is it? What do I have?" she asks. The dermatologist's answer sounds very cold: "Nothing to worry about. Just take the medicines and it will pass." 